\title{
Analysis on the Paths of the Psychological Training in the Piano Teaching
}

\author{
Le Yu
}

\author{
Music College of Changchun University, Changchun city Jilin \\ province, 130022, China
}

\begin{abstract}
Piano teaching is a highly artistic, technical and scientific job. It must follow the teaching psychology principles. This paper explores the importance of psychological training in the piano teaching and discusses the common psychological problems in piano teaching. This paper puts forward the paths of psychological training in piano teaching, including stimulating the interest of learning, cultivating the habit of thinking and improving the expression of art, to provide some references for the relative researchers.
\end{abstract}

Keywords:psychological training, piano teaching, piano performance

\section{Introduction}

Piano teaching requires teachers to explore the scientific teaching methods and rules. Psychology is the theoretical basis of education and teaching. Piano teaching should follow the basic principles of psychology. The teachers engaged in Piano Teaching in the theory of Professor students with solid and superb playing skills at the same time, also need psychological characteristics, according to the students in the teaching in the process of learning, playing as reflected in the law and the phenomenon of make a careful and reasonable teaching plan, select the appropriate teaching materials and teaching methods of science effectively, make the students master the comprehensive piano skills at the same time, also has the good psychological quality and healthy psychological quality. Therefore, it is very important to pay attention to students' psychological training 
in piano teaching. Piano teaching should follow the principles of psychology. According to the psychological characteristics of students and the law reflected in the process of learning. We should make a careful and long-term teaching plan and select the appropriate teaching materials, applying scientific and effective teaching methods, to enable students to master the comprehensive skills at the same time. It also has the good psychological quality and healthy psychological quality. In this paper, from the psychological point of view, we focus on the analysis of the students in the piano practice in the formation of undesirable psychological phenomena, and discuss the psychological trainingmethods in the piano teaching.

\section{Significance of psychological training in the piano teaching}

The piano teaching theory and teaching practice is often affected by the restrictions, mostly from the teacher's personal experience and experience or traditional authority view, classroom teaching content generally focused on the basic teaching \& playing method and music style and aesthetic interpretation. This is undoubtedly the most important content of the piano teaching system. The teachers teach the students a few tracks, to help students solve the current target examination, concerts. Piano teaching should provide students with an effective guiding tool, so that students become independent learners, to help them get a lifetime of growth and shape a lifelong hobby. A lot of people on the piano learning there is a misunderstanding that the piano practice is a few hours of finger movement, in fact, learning the piano is in the development of the brain. The trick is to develop a faster process of linking the body to produce more brain cells that control finger movement and memory. The basis of all music practice determines the quality of music activities. To cultivate a high level professional or amateur piano talent, is a difficult system engineering, which contains psychological skills and skills of learners also need hard temper, deeply rooted in the broad cultural literacy and music theory. Piano performance from nature, it is a complicated psychological basis under the control of skill activities, not only the physiological mechanism, it not only requires the player to possess certain skills, but also have a certain psychological skills. The skill is a series of external action to perfect a reasonable method of operation activities, gradually formed and subsequently consolidated by the correct practice and long-term practice. Thelack of psychological training in piano teaching is not complete.

\section{Common psychological problems in the piano teaching}

\subsection{Inferiority psychology}

The piano technique is very complex and difficult. The students will have to face various difficulties, hard work. Inferiority and fear, is generally caused by exercise in technology. The technical obstacles in practice, sometimes more often than it used to solve the practice is more important. Inferiority performance for personal ability and quality make the low evaluation. Inferiority students 
everywhere are not as good as others, despair, frustration often encountered in learning, learning to play the piano to produce a sense of fear, even for those tasks that a little effort, but also give up easily. Some students always encountered technical difficulties with fear, skeptical of their ability to solve problems, so take the method of passive avoidance to compensate for confidence. Due to the lack of self-confidence of inferiority and fear, is the student learning and playing the biggest psychological barriers. Teachers cannot be equal treatment of students, the results of those who prefer to coach, preference for them, poor performance of the poor, discrimination, so that when they are negative textbooks. They make the wrong move demonstration, which causes the alienation feelings between teachers and students, making them the pleasure of learning gradually disappear. Teachers should help them to understand and understand the purpose of piano learning, and establish self-confidence.

\subsection{Dependence psychology}

Dependence is a manifestation of personality. Its characteristic is not assertive, lack of confidence, always want to rely on others and not independence or selfsufficiency. Piano teaching is usually a form of teaching, it is helpful to teachers teaching; but on the other hand, it is easy to encourage students' psychological dependence. The student teachers are normal, but all learning behaviour depends on teachers on Teachers' life, easy to form the teaching of mechanical passive influence, initiative, enthusiasm and creativity of learning. In addition, many young students have a strong dependence on their parents, whether it is the basic requirements of the teacher or the spectrum, and even practice also need to urge parents. The results of learning are very passive, little progress. In piano teaching, the students generally have psychological dependence on teachers, lack of active learning and creative spirit. Students expect teachers to summarize and Piano problems to be arranged to recount, highlight the key difficulty and key. Bachelor teacher provides a detailed demonstration of problem solving, accustomed to step by step to imitate mechanically. If things go on like this, students' spirit is depressed, creating potential was killed, the study enthusiasm and initiative lost gradually. In this case, the students' psychological dependence, if not promptly corrected, unchecked, in the personality, may lead to the formation of dependent personality disorder type. In piano teaching, it is necessary to guide students to overcome the psychological dependence.

\subsection{Nervousness psychology}

Piano playing is the art of time as well as other performing arts. It is characterized by the performer's perfect and creative performance in the moment of performance. But in reality, the students play a variety of problems. Piano performance, although it is a series of physical movements, and contains a certain technical, but the psychological guidance is not to be ignored. The change of psychology in the process of playing directly leads to the success of the performance. There are many kinds of reasons and ways of expression, which can be divided into two categories, which are the technical and psychological stress. 
The harmfulness of psychological stress is far more than the technical tension. Public performance, the brain blank, forget the score or lyrics, muscle tension, loss of action activity, which is caused by psychological stress. Psychological stress can be divided into two types of temporary and long-term tension. The psychological abnormality caused by the objective environment is called temporary psychological stress. This example tracks too hard, practice and technology together, will make the performers feel powerless, lack of confidence and nervousness. The heart is too heavy for fear of success and failure, gain and loss, error, emotions too tight, usually handy, which can recite fluently from memory song, once in power performance. It is very simple also wrong one after another. The long term mental nervousness psychology is led by the personality and temperament of the learners.

\section{Paths of the psychological training in the piano teaching}

\subsection{Stimulate learning interest}

Interest is the positive attitude and psychological tendency in the participation of activities. Interest is the great power of learning, and it is the spirit of students' active learning and research. As a kind of psychological tendency, there are personality differences. Some students are interested in music and piano, while others are not interested in music and piano. For this innate interest difference, the degree of compensation is limited. In the learning phase, especially children, often of interest is the decisive factors in piano learning, low interest or no interest in other children must needs induced, it may be engaged in piano learning activities. But once the lack of interest in motivation occurs, enthusiasm and efforts to study the extent and difficulties encountered will inevitably be adversely affected. The specialty of piano teaching makes many teachers think that the piano teaching is more professional, the other hand, it is believed that all the students should be in accordance with the requirements of professional standards for whatever purpose. However, the effect of teaching, on the one hand, students cannot really complete the task, on the other hand too professional requirements, so that students have to pay too much effort to lose interest in the piano. Therefore, it is necessary for students to like music, like the piano for the purpose of arranging the teaching process and requirements, students naturally accept piano education and then consider the appropriate introduction of higher professional requirements. The piano lessons are interesting and colorful, so that students can master the skills in music. In order to let the students sincerely willing to practice the piano, the first thing to let him interested in what he played, it is necessary to resolutely abandon the original dull boring teaching mode. Teachers should use vivid language, accurate and expressive rhythm to guide students to understand and perform the music more depth and detailed. 


\subsection{Cultivate mental habit}

The biggest failure of traditional teaching lies in ignoring the generation process of knowledge. It only pays attention to the result, giving the students as much as possible. In fact, the process of knowledge generation is more important. There is a profound thinking process and reasoning process. Convergent thinking is a kind of way of thinking, which has the direction, scope and organization to find the correct answer from the known information. It is an effective way of thinking that can integrate and refine information. The network can provide us with a large number of integrated information, and the process of dealing with this information is conducive to the training of students' aggregation thinking. In order to do this, first guide students to eliminate the interference in combination with network, focused on the current research are learning problemsto contain those who have nothing to do with the study of the news column or more. Teachers should help students find those and research issues are closely related and high information density in the website, information about the web page, by title or excerpt segment. There is no need to open one by one. Successful students have strong self-confidence, in practice and performance in a proactive. They are willing to accept the opinions and evaluations of others, love open to play. They don't take piano learning as a burden, but as a means to show their ability. The failure of students is timid, self-esteem, not willing to accept others' criticism. Too often their own capacity constraints in practice can reach below the level, imperceptibly belittle their ability. Positive thinking habits will help students improve piano skills.

\subsection{Enhance expressive force}

If there is no rich imagination, there is no music performance. It also goes against the will of the music to express emotions. Piano players need to play their own imagination and creativity, playing in the process of playing music, need to understand the emotional connotation in music composers devoted, and through their own emotional perception, examine the piano juice to deduct, mining of piano and the profound emotional connotation of intangible aesthetic feeling to the audience in the process of piano teaching, many students can only play music leaves for skilled, but cannot effectively play imagination and creativity, lack of understanding of the connotation of creative works and artistic appeal. In this situation, teachers need to carry out the demonstration and interpretation of the students, so as to show the unique charm of the piano music for the students. In the teaching of piano performance, teachers can guide the students to think and create. In the actual teaching, the teacher shows the music performance to the students through the imitation sounds of various birds, and displays the exquisite sound through the fingers. Around the turn of the hand to play the music sound crescendo, the piano in the climax followed until after the climax, the birds singing clears, showing the silence in the forest and no distant play before the climax of each other. Students under the guidance of teachers, will fully mobilize the imagination, vivid picture in mind birds singing, which can show the vitality 
of life in the fry played. By stimulating the students' imagination and creativity, students can form a good artistic accomplishment, so as to better play the piano. Therefore, teachers can through the wonderful and vivid demonstration to inspire students and arouse students' artistic creativity and imagination.

\section{Conclusion}

Piano teaching and learning psychology are inseparable. Only the psychological thing is the essence of the music. In piano teaching, teachers need to observe and understand all kinds of psychological phenomena in the students' learning, so as to select the appropriate training methods and carry out positive psychological guidance. Only in this way can we improve students' piano skills.

\section{References}

[1] Chen Jing, The Application of the Incentive Theoryin Management Psychology in Piano Teaching, Journal of Yuxi Normal University, 30(8), pp. 6870, 2014.

[2] Liu Jia, Application of music psychology in the teaching of piano, Journal of Jiamusi Vocational Institute, (4), pp. 53, 2013.

[3] Fan Jingjing, Status and Application of Educational Psychology in Piano Teaching, The Guide of Science \& Education, (4), pp. 117+156, 2014.

[4] Hu Duoge, The Application of Musical Psychology in Piano Teaching, Journal of Henan Institute of Education (Philosophy and Social Sciences), 30(3), 2011. 